\title{
Produtividade de minicepas e enraizamento de miniestacas de clones de erva-mate (Ilex paraguariensis A. St.-Hil.)
}

\author{
Productivity of mini-stumps and rooting of mini-cuttings of erva mate (Ilex \\ paraguariensis A. St.-Hil.) clones
}

\section{Nathalia Pimentel ${ }^{\text {I }}$, Kelen Haygert Lencina ${ }^{\mathrm{II}}$, Paula Kielse ${ }^{\mathrm{II}}$, Mhaiandry Benedetti

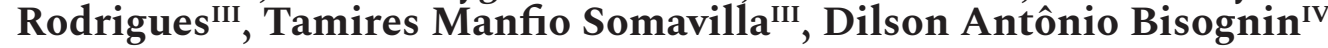

\begin{abstract}
Resumo
O objetivo deste trabalho foi avaliar o efeito de épocas do ano e de clones na produtividade das minicepas e no enraizamento de miniestacas de erva-mate (Ilex paraguariensis A. St.-Hil.) tratadas ou não com ácido indolbutírico (AIB). Com esta finalidade, nas quatro épocas do ano realizou-se a coleta de brotos das minicepas de quatro clones de erva-mate, sendo que em cada coleta foi avaliada a porcentagem de sobrevivência das minicepas e o número de miniestacas obtidas por minicepa. Posteriormente, os brotos foram seccionados em miniestacas de gema única, as quais foram ou não tratadas com $2000 \mathrm{mg} \mathrm{L}^{-1}$ de AIB. Aos 30 e 60 dias foram avaliadas as porcentagens de sobrevivência, enraizamento e calogênese, número e comprimento das raízes. As minicepas dos quatro clones de erva-mate apresentaram alta sobrevivência, além de produção constante de miniestacas dos clones 06SM17, 06SM12 e 06SM15 durante as quatro épocas do ano. O tratamento com AIB não incrementa o enraizamento das miniestacas de erva-mate. $O$ processo rizogênico das miniestacas varia conforme o genótipo e a sazonalidade. O clone 06SM15 apresenta a maior capacidade rizogênica nas quatro épocas do ano. As melhores porcentagens de enraizamento são verificadas nas épocas do outono e/ou inverno para os quatro genótipos avaliados.
\end{abstract}

Palavras-chave: Ilex paraguariensis; Minijardim clonal; Épocas do ano; Ácido indolbutírico

\begin{abstract}
The objective of this work was to evaluate the effect of season and clone in the productivity of the ministumps and the rooting of mini-cuttings of erva mate (Ilex paraguariensis A. St.-Hil.) treated or not with indolbutyric acid (IBA). Mini-cuttings were collected from mini-stumps of four clones during the four seasons of the year. In each collection, it was evaluated the percentage of mini-stumps survival and the number of mini-cuttings obtained per mini-stump. Single-budded mini-cuttings were treated or not with $2000 \mathrm{mg} \mathrm{L}^{-1}$ IBA before planting. At 30 and 60 days, the percentages of survival, rooting and callus formation in mini-cuttings, the number and length of roots were evaluated. The mini-stumps of the four erva mate clones showed high survival. The clones 06SM17, 06SM12 and 06SM15 had a uniform production of minicuttings per mini-stump during the four collection times. IBA treatment is not necessary for mini-cutting rooting of these clones. The mini-cutting rooting varied with the evaluated clone and collection time. The clone 06SM15 had the highest rhizogenesis capability in the four collection times. The highest rooting percentage was obtained during fall and winter seasons for the four clones.
\end{abstract}

Keywords: Ilex paraguariensis; Mini - clonal hedge; Collection time; Indolbutyric acid

Engenheira Florestal, MSc., Doutoranda do Programa de Pós-Graduação em Engenharia Florestal, Centro de Ciências Rurais, Universidade Federal de Santa Maria, Av. Roraima, 1000, CEP 97105-900, Santa Maria (RS), Brasil. nathaliapimentel@outlook.com (ORCID: 0000-0002-2584-1223) Federal de Santa Maria, Av. Roraima, 1000, CEP 97105-900, Santa Maria (RS), Brasil. nathaliapimentel@outlook.com (ORCID: 0000-0002-2584-1223)
Engenheira Florestal, Dra., Centro de Ciências Rurais, Universidade Federal de Santa Maria, Av. Roraima, 1000, CEP 97105-900, Santa Maria (RS), Brasil. khaygert@gmail.com (ORCID: 0000-0001-5777-5569)/ paulinhakielse@gmail.com (ORCID: 0000-0003-1928-3365)

III Engenheira Florestal, Mestranda do Programa de Pós-Graduação em Engenharia Florestal, Centro de Ciências Rurais, Universidade Federal de Santa Maria, Av. Roraima, 1000, CEP 97105-900, Santa Maria (RS), Brasil. mhayforest@gmail.com (ORCID: 0000-0002-9171-0563)/ tamiresmanfio@ yahoo.com.br (ORCID: 0000-0001-5507-5008)

Iv Engenheiro Agrônomo, PhD., Professor do Departamento de Fitotecnia, Centro de Ciências Rurais, Universidade Federal de Santa Maria, Av. Roraima, 1000, CEP 97105-900, Santa Maria (RS), Brasil. dilson.bisognin@ufsm.br (ORCID: 0000-0002-4754-9661) 


\section{Introdução}

A erva-mate (Ilex paraguariensis A. St.-Hil.) é uma espécie nativa da floresta ombrófila mista, pertencente à família Aquifoliaceae, a qual se destaca por ser importante fonte de renda em alguns países da América do Sul, tais como Paraguai, Argentina e Brasil (SANSBERRO et al., 2000). Esta espécie também apresenta grande importância cultural, sendo consumido nos países sul-americanos em função da tradição adquirida das populações nativas (CARDOZO JUNIOR; MORAND, 2016). O principal modo de consumo da erva-mate é na forma de chimarrão e chás, porém, as folhas apresentam outras diversas aplicações industriais, tais como extratos solúveis para bebidas, corante, conservante de alimentos e matéria-prima para produtos de higiene e cosméticos (SAMBIASSI; ESCALADA; SCHMALKO, 2002).

A erva-mate encontra-se integrada em diversos sistemas produtivos, demandando constante produção de mudas para atender os plantios comerciais, que visam à obtenção de matéria-prima (SILVA;BICCA NETO; FOLTRAN, 2007). Entretanto, ervais de baixa produtividade têm sido estabelecidos, provavelmente, devido à utilização de mudas de baixa qualidade. Isso se deve ao fato da maior parte das mudas desta espécie ser produzida por sementes de baixa qualidade genética (SANTIN et al., 2008), resultado da seleção apenas para o genitor feminino e consequentemente da relação genética de meios-irmãos das plantas produzidas. Além disso, as sementes de erva-mate apresentam imaturidade do embrião e dormência tegumentar, fatores que dificultam a produção de mudas seminais (FOWLER; STURION, 2000; WENDLING; SANTIN, 2015).

Diante das limitações verificadas para a produção de mudas seminais, a propagação vegetativa se apresenta como alternativa viável para a multiplicação de erva-mate (WENDLING; SANTIN, 2015). Entre as técnicas, destaca-se a miniestaquia, a qual consiste na manutenção de plantas em sistemas de minijardim clonal para o fornecimento de brotações (ALFENAS et al., 2009), que darão origem as miniestacas. Diversos estudos têm sido realizados com esta técnica, visando à obtenção de protocolos eficientes para a espécie (WENDLING; DUTRA; GROSSI, 2007; WENDLING; DUTRA, 2008; BRONDANI et al., 2008b; KRATZ et al., 2015), no entanto, baixos índices de enraizamento adventício dos propágulos vegetativos são observados até os dias atuais (WENDLING; SANTIN, 2015).

O sucesso da miniestaquia é dependente de alguns fatores como a produtividade das minicepas e o enraizamento adventício das miniestacas. A produtividade das minicepas pode ser expressa pela razão entre o número total de miniestacas e o número de minicepas (FERRIANI; ZUFFELLATO-RIBAS; WENDLING, 2010), sendo influenciada, entre outros fatores, pelo tipo de minijardim clonal, manejo nutricional utilizado (ALFENAS et al., 2009) e a sazonalidade. A sazonalidade se refere aos efeitos característicos de uma época ou estação do ano, podendo influenciar no enraizamento adventício dos propágulos vegetativos (HARTMANN et al., 2011). Quanto aos efeitos da sazonalidade, não há estudos que abordem a interferência das épocas do ano na produtividade de minicepas e no processo rizogênico de miniestacas de erva-mate.

Apesar de se esperar que os efeitos da sazonalidade sejam minimizados pelas condições ambientais controladas da miniestaquia, respostas distintas de produtividade das minicepas e de enraizamento das miniestacas poderão ocorrer, principalmente, devido à variação entre genótipos (BORGES et al., 2011). Para a produção massal de mudas são almejados materiais genéticos que apresentam altas taxas de multiplicação ao longo do ano, associadas a elevadas porcentagens de enraizamento adventício. Nesse sentido, torna-se importante o estudo e a identificação de clones que respondam satisfatoriamente às condições ambientais disponíveis, permitindo o uso promissor da técnica de miniestaquia.

O enraizamento adventício também pode ser influenciado pelo estado nutricional dos propágulos vegetativos a serem regenerados em novas plantas, uma vez que o status nutricional determina a quantidade de carboidratos, auxinas e outros compostos necessários para a iniciação e desenvolvimento da rizogênese (CUNHA et al., 2009). Outro fator que pode afetar o 
processo rizogênico é o uso de fitorreguladores, sendo o ácido indolbutírico (AIB) uma auxina comumentemente utilizada na propagação vegetativa com a finalidade de estimular a formação do sistema radicial (BRONDANI et al., 2008a). Para erva-mate, há décadas está sendo estudado o uso do AIB no enraizamento de estacas ou miniestacas (BITENCOURT et al., 2009) porém, as respostas têm variado conforme o material genético utilizado, propiciando resultados tanto positivo quanto negativo (NAGAOKA et al., 2013).

Diante do exposto e considerando a importância da propagação vegetativa para a produção de mudas de erva-mate, o objetivo deste trabalho foi avaliar o efeito de épocas do ano e de clones na produtividade das minicepas e no enraizamento de miniestacas de erva-mate tratadas ou não com AIB.

\section{Material e métodos}

O estudo foi realizado de abril de 2014 a janeiro de 2015, em casa de vegetação climatizada (temperatura máxima de $37^{\circ} \mathrm{C}$ ) do Núcleo de Melhoramento e Propagação Vegetativa de Plantas, Departamento de Fitotecnia da Universidade Federal de Santa Maria. O experimento foi conduzido em minijardim clonal de erva-mate com idade aproximada de três anos, constituído de minicepas dos clones 06SM17, 06SM15 e 06SM12, originários da germinação in vitro de embriões zigóticos (HORBACH et al., 2011), e o clone 10SM07, oriundo da estaquia de brotos epicórmicos de árvores com, aproximadamente, 20 anos de idade.

O minijardim clonal de erva-mate foi estabelecido em quatro bandejas de polietileno (55 x 34 x $15 \mathrm{~cm}$ ), cada uma contendo mudas de um clone, plantadas no espaçamento de $10 \times 10 \mathrm{~cm}$, em sistema fechado de cultivo sem solo e fertirrigação por inundação, seguindo metodologia descrita por Bandinelli et al. (2013). A solução nutritiva foi fornecida duas vezes por dia, durante 15 minutos, com o auxílio de um programador digital e uma bomba submersa de baixa vazão, até o encharcamento completo do substrato e formação de uma lâmina superficial de solução. A solução nutritiva foi constituída pelas seguintes quantidades de macronutrientes $\left(\mathrm{mmol} \mathrm{L}^{-1}\right)$ : 4,09 de nitrato de potássio; 6,66 de nitrato de cálcio; 11,18 de sulfato de magnésio; 0,96 de nitrato de amônio; 0,92 de monofosfato de potássio e 1,12 de ferro quelatizado 5\%. Os micronutrientes foram adicionados à solução nutritiva em uma mistura previamente preparada contendo (mmol $\mathrm{L}^{-1}$ ): 0,10 de molibdato de sódio; 0,60 de ácido bórico; 0,83 de sulfato de cobre; 0,82 de sulfato de manganês e 0,18 de sulfato de zinco. $\mathrm{O}$ pH da solução nutritiva foi mantido entre 5,5 e 6,0 e a condutividade elétrica em $1,5 \mathrm{dS} \mathrm{m}^{-1}$.

As coletas das brotações das minicepas de erva-mate foram realizadas nas estações do ano: outono (abril de 2014), inverno (julho de 2014), primavera (outubro de 2014) e verão (janeiro de 2015). O experimento foi delineado em esquema fatorial 4 x 4 (clones $\mathrm{x}$ épocas do ano) no delineamento inteiramente casualizado, com números de repetições variando entre 6 e 10, sendo que cada minicepa foi considerada uma repetição. Em cada coleta foi avaliada a porcentagem de sobrevivência das minicepas e o número de miniestacas com $2,0 \mathrm{~cm}$ de comprimento produzidas por minicepa.

Para o enraizamento, as porções apicais e medianas das brotações coletadas das minicepas de erva-mate (Figura 1A) nas quatro épocas do ano foram seccionadas em miniestacas de gema única, com, aproximadamente, $2,0 \mathrm{~cm}$ de comprimento e contendo uma folha reduzida em $50 \%$ da sua área original (Figura 1B). As miniestacas foram ou não tratadas com solução hidroalcoólica de AIB na concentração de $2000 \mathrm{mg} \mathrm{L}^{-1}$, por 10 segundos, e cultivadas em bandejas de isopor de 128 alvéolos contendo igual proporção de substrato comercial à base de casca de pinus, vermiculita média e areia de granulometria grossa (Figura 1C), conforme os melhores resultados obtidos em ensaios preliminares. O enraizamento das miniestacas foi realizado em câmara úmida, com umidade relativa do ar de, aproximadamente, $85 \%$, fornecida por nebulização automatizada 8 vezes ao dia por 1 minuto (Figura 1D), com fluxo de ar de $10 \mathrm{~m}^{3} / \mathrm{min}$. 
Figura 1 - Broto de erva-mate (Ilex paraguariensis A. St. -Hil.) formado em minicepa estabelecida em minijardim clonal (A). Miniestaca de gema única com uma folha reduzida em $50 \%$ da sua área original (B) cultivada em bandejas de isopor contendo igual proporção de substrato comercial à base de casca de pinus, vermiculita média e areia de granulometria grossa $(C)$ e câmara úmida de enraizamento $(D)$. Barra $=2 \mathrm{~cm}$.

Figure 1 - Shoots of erva mate (Ilex paraguariensis A. St. -Hil.) formed in mini-stumps established in mini-clonal hedge (A). Mini-cutting of single bud with a leaf reduced by $50 \%$ of its original area (B), cultivation in trays containing the same proportion of pine bark-based commercial substrate, medium vermiculite and coarse sand $(C)$ and wet chamber $(D) . B a r=2 \mathrm{~cm}$.

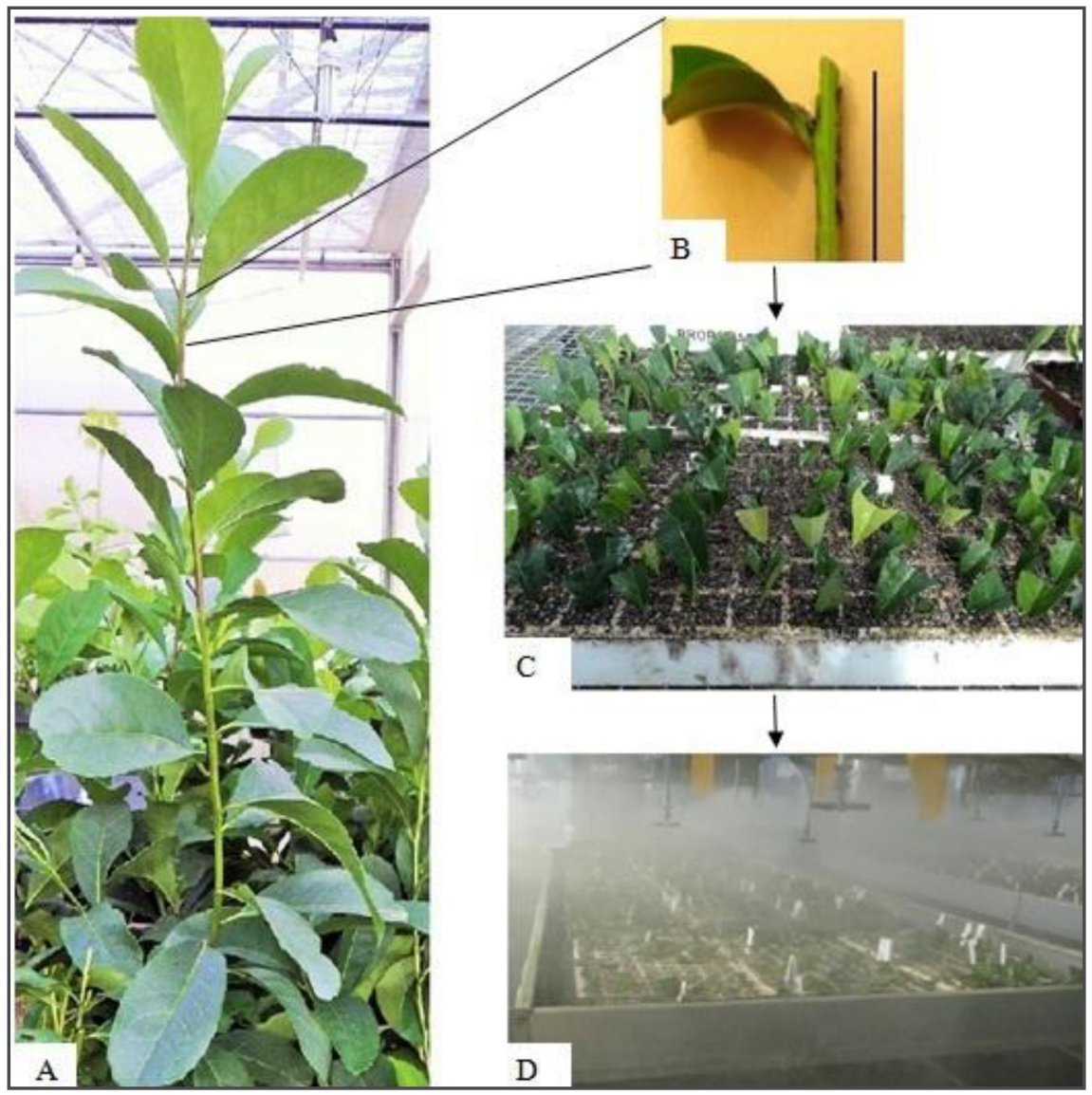

Fonte: Autores (2019)

Source: Authors (2019)

O experimento foi um fatorial $4 \times 4 \times 2$ (épocas do ano x clones x concentrações de AIB) no delineamento inteiramente casualizado, com 10 repetições contendo 16 a 40 miniestacas por repetição, conforme a quantidade de miniestacas produzidas por cada clone em cada época do ano. Aos 30 e 60 dias de cultivo foram avaliadas as porcentagens de sobrevivência, enraizamento e calogênese, o número e comprimento das raízes. A porcentagem de sobrevivência foi obtida através da contagem das miniestacas vivas e a porcentagem de enraizamento contabilizando as miniestacas que apresentavam pelo menos uma raiz adventícia com comprimento igual ou superior a $0,1 \mathrm{~cm}$. 
Aos 60 dias de cultivo também foi contabilizado o número de miniestacas enraizadas por minicepa de erva-mate. Esta variável foi analisada em fatorial 4 x 4 (clones x épocas do ano) no delineamento inteiramente casualizado, com números de repetições variando entre 6 e 10, sendo que cada minicepa foi considerada uma repetição.

Para atender a normalidade, os dados de porcentagem foram transformados para arcosseno $\sqrt{x / 100}$ e de contagem e comprimento para $\sqrt{x+0,5}$ e submetidos à análise de variância. As médias dos tratamentos com diferenças significativas foram comparadas pelo Teste de Tukey com o auxílio do programa ESTAT (UNESP - Jaboticabal) e probabilidade de erro de 5\%.

\section{Resultados e discussão}

As minicepas de erva-mate apresentaram 100\% de sobrevivência aos 10 meses de manejo do minijardim clonal, o que indica que o sistema adotado, o manejo e as condições nutricionais oferecidas foram adequados. Segundo Hartmann et al. (2011), o manejo do minijardim clonal é muito importante para a sobrevivência da planta fornecedora de propágulos vegetativos, sendo um dos principais fatores que afetam a propagação vegetativa. Outros estudos também relataram elevada sobrevivência das minicepas de erva-mate mantidas em minijardim clonal, apresentando média de 90\% (WENDLING; DUTRA, 2008) e 93,8\% (WENDLING; DUTRA; GROSSI, 2007) das minicepas vivas após a realização de coletas sucessivas de brotações.

Para o número de miniestacas por minicepa, houve interação significativa $(\mathrm{p}<0,05)$ entre os clones e as épocas do ano. A maior produtividade foi observada no clone 10SM07 coletado no verão, com 145,8 miniestacas por minicepa, sendo significativamente superior às demais épocas, e o clone 06SM12 no outono, com 121,5 miniestacas por minicepa em intervalo de 90 dias (Tabela 1). Para o clone 06SM12, apesar do elevado número de miniestacas produzidas no outono, a época não apresentou efeito significativo. O mesmo comportamento foi observado nos clones 06SM17 e 06SM15, para os quais não houve efeito das épocas do ano na produtividade de miniestacas por minicepa (Tabela 1).

Tabela 1 - Número de miniestacas por minicepa de clones de erva-mate (Ilex paraguariensis A. St. -Hil.) coletadas em diferentes épocas do ano, com intervalo de 90 dias entre cada coleta.

Table 1 - Number of mini-cuttings by mini-stumps of clones of erva mate (Ilex paraguariensis A. St. -Hil.) collected at different times of the year, with interval of 90 days between each collection.

\begin{tabular}{lcccc}
\hline \multirow{2}{*}{ Clones } & \multicolumn{4}{c}{ Épocas do ano } \\
\cline { 2 - 5 } & Outono & Inverno & Primavera & Verão \\
\hline 10SM07 & $79,3 \mathrm{Bab}^{*}$ & $79,6 \mathrm{Ba}$ & $70,1 \mathrm{Ba}$ & $145,8 \mathrm{Aa}$ \\
06SM17 & $78,3 \mathrm{Aab}$ & $73,8 \mathrm{Aa}$ & $65,8 \mathrm{Aa}$ & $69,4 \mathrm{Abc}$ \\
06SM15 & $45,6 \mathrm{Ab}$ & $46,6 \mathrm{Aa}$ & $43,3 \mathrm{Aa}$ & $50,7 \mathrm{Ac}$ \\
06SM12 & $121,5 \mathrm{Aa}$ & $87,0 \mathrm{Aa}$ & $80,1 \mathrm{Aa}$ & $97,1 \mathrm{Ab}$ \\
Média & 81,18 & 71,78 & 64,86 & 90,78 \\
CV (\%) & & & & \\
\hline
\end{tabular}

*Valores seguidos de mesma letra, maiúscula na horizontal e minúscula na vertical, não diferem pelo teste de Tukey a $5 \%$ de probabilidade de erro. 
A produção contínua de miniestacas por minicepa de erva-mate dos clones 06SM17, 06SM15 e 06SM12 nas quatro épocas do ano, pode estar associada à juvenilidade dos mesmos, os quais são oriundos da cultura de embriões zigóticos, ou seja, do rejuvenescimento natural, uma das mais eficazes técnicas desenvolvida para rejuvenescer ou manter a juvenilidade das plantas (WENDLING; TRUEMAN; XAVIER, 2014). O estádio juvenil possibilita o maior crescimento vegetativo da planta (GREENWOOD; DAY; SCHATZ, 2010) e, por conseguinte, maior produtividade de brotações e de miniestacas por minicepa. Já as minicepas do clone 10SM07 são oriundas da estaquia de árvore-matriz adulta de erva-mate e, portanto, apresentam maior grau de maturação e consequentemente perda de vigor em alguns períodos de desenvolvimento (WENDLING; XAVIER, 2001). Este fator provavelmente foi responsável pela inferior produção de miniestacas de erva-mate deste clone nas estações do outono, inverno e primavera, quando comparados ao verão (Tabela 1).

Os resultados deste estudo mostram claramente que a produtividade das minicepas de erva-mate é dependente do clone. Independentemente da época do ano, o clone 06SM15 apresentou a menor produtividade de miniestacas por minicepa de erva-mate nas quatro épocas de coleta (Tabela 1). Este resultado poderá ter ocorrido devido à maior persistência da dominância apical do clone mesmo após a decapitação do ápice, o que poderá justificar a emissão de menor número de brotações nas minicepas (TITON et al., 2003). Brondani et al. (2012) também observaram diferença entre três clones de Eucalyptus benthamii x Eucalyptus dunnii quanto à produtividade de miniestacas por minicepa. Como alternativa para clones que apresentam baixa produtividade de miniestacas, como o clone 06SM15, pode-se utilizar o manejo das minicepas com podas mais frequentes. As podas favorecem o desenvolvimento de gemas laterais, estimulando bifurcações que poderão aumentar a área de coleta de material propagativo.

De modo geral, o número de miniestacas produzidas por minicepa de erva-mate, com intervalo de 90 dias entre cada coleta, variou de 43,3 a 145,8 , conforme o clone e a época do ano (Tabela 1). Este resultado é muito satisfatório comparado com o observado por Wendling, Dutra e Grossi (2007), no qual foi verificada uma produtividade de 4,4 miniestacas por minicepa de erva-mate a cada 39 dias de coleta em sistema semi-hidropônico. A maior produção de miniestacas observada no presente estudo pode estar relacionada com o fato das minicepas possuírem três anos de idade e pleno estabelecimento e crescimento nas condições ambientais e nutricionais do sistema de minijardim clonal. Outro fator que poderá estar relacionado com a maior produtividade de miniestacas é a formulação da solução nutritiva fornecida as minicepas, a qual possui aproximadamente o dobro da concentração de $\mathrm{N}$ na forma de nitrato do que a solução nutritiva utilizada por Wendling, Dutra e Grossi (2007). $\mathrm{O}$ nitrogênio é o nutriente que pode interferir de forma significativa na produtividade de miniestacas nos minijardins clonais (ROSA et al., 2009), pois proporciona incremento no teor de clorofila (REZENDE et al., 2015) e, consequentemente, maior desenvolvimento da parte aérea em plantas de espécies florestais (MARQUES et al., 2004). O efeito do aumento das concentrações de nitrogênio na produtividade de miniestacas também foi observada por Rosa et al. (2009) em minicepas de Eucalyptus dunnii mantidas em sistema de minijardim clonal. É importante mencionar que a produtividade de miniestacas não garante alta taxa de multiplicação, pois esta depende da porcentagem de enraizamento.

No enraizamento das miniestacas, não houve interação significativa entre os tratamentos com AIB, os clones e as épocas do ano $(\mathrm{p}>0,05)$ para todas as variáveis estudadas, aos 30 e 60 dias de cultivo. As concentrações de AIB apresentaram efeito principal significativo nas porcentagens de enraizamento e calogênese, número e comprimento das raízes, aos 30 dias de avaliação (Tabela 2). As miniestacas tratadas com $2000 \mathrm{mg} \mathrm{L}^{-1}$ de AIB apresentaram maior porcentagem de enraizamento e calogênese, número e comprimento das raízes. Entretanto, aos 60 dias de cultivo não houve diferença significativa entre as miniestacas tratadas ou não com AIB para todas as variáveis analisadas (Tabela 2). Esse 
resultado demonstra que para os clones de erva-mate estudados, o tratamento com AIB não incrementou o enraizamento das miniestacas quando avaliado aos 60 dias, mas favoreceu a rizogênese nos primeiros 30 dias. Resultado semelhante foi observado em estacas caulinares de erva-mate provenientes de brotações de ano (BITENCOURT et al., 2009), nos quais não houve efeito do AIB no enraizamento adventício dos propágulos vegetativos. Cabe ressaltar que, na avaliação de 30 dias, a porcentagem de miniestacas de erva-mate enraizadas é baixa, independentemente se tratadas ou não com AIB, apresentando média de 0,61\% (Tabela 1). Este resultado indica que é necessário que as miniestacas sejam cultivadas em ambiente de enraizamento por período superior aos 30 dias de cultivo, possibilitando a obtenção de um maior número de miniestacas de erva-mate enraizadas e consequentemente maior número de mudas produzidas.

Tabela 2 - Porcentagens de sobrevivência, calogênese e enraizamento, número e comprimento das raízes formadas em miniestacas de erva-mate (Ilex paraguariensis A. St. -Hil.) não tratadas ou tratadas com ácido indolbutírico (AIB) $\left(0\right.$ e $2000 \mathrm{mg} \mathrm{L}^{-1}$ respectivamente), aos 30 e 60 dias de cultivo.

Table 2 - Percentages of survival, calogenesis and rooting, number and length of roots formed in mini-cuttings of erva mate (Ilex paraguariensis A. St. -Hil.) untreated or treated with indolbutyric acid (IBA) (0 and $2000 \mathrm{mg} \mathrm{L}^{-1}$ respectively) at 30 and 60 days of cultivation.

\begin{tabular}{|c|c|c|c|c|c|}
\hline AIB & $\begin{array}{c}\text { Sobrevivência } \\
(\%)\end{array}$ & $\begin{array}{c}\text { Enraizamento } \\
(\%)\end{array}$ & $\begin{array}{c}\text { Calogênese } \\
(\%)\end{array}$ & $\begin{array}{c}\text { Número de } \\
\text { raízes }\end{array}$ & $\begin{array}{c}\text { Comprimento de } \\
\text { raízes } \\
(\mathbf{c m}) \\
\end{array}$ \\
\hline & \multicolumn{5}{|c|}{ Avaliação aos 30 dias de cultivo } \\
\hline 0 mg L $\mathbf{~}^{-1}$ & $73,28 a^{*}$ & $0,10 \mathrm{~b}$ & $44,14 \mathrm{~b}$ & $0,21 \mathrm{~b}$ & $0,05 \mathrm{~b}$ \\
\hline $\begin{array}{l}2000 \mathrm{mg} \\
\mathrm{L}^{-1}\end{array}$ & $75,70 \mathrm{a}$ & $1,12 \mathrm{a}$ & $47,72 \mathrm{a}$ & $1,00 \mathrm{a}$ & $0,20 \mathrm{a}$ \\
\hline Média & 74,49 & 0,61 & 45,93 & 0,60 & 0,13 \\
\hline \multirow[t]{2}{*}{$\mathrm{CV}(\%)$} & 16,89 & 130,17 & 24,50 & 45,25 & 26,23 \\
\hline & \multicolumn{5}{|c|}{ Avaliação aos 60 dias de cultivo } \\
\hline 0 mg $\mathbf{L}^{-1}$ & $65,33 \mathrm{a}$ & $16,30 \mathrm{a}$ & $56,00 \mathrm{a}$ & $2,44 \mathrm{a}$ & $0,52 \mathrm{a}$ \\
\hline $\begin{array}{l}2000 \mathrm{mg} \\
\mathrm{L}^{-1}\end{array}$ & 65,14 a & $17,71 \mathrm{a}$ & 55,79 a & $2,45 \mathrm{a}$ & $0,60 \mathrm{a}$ \\
\hline Média & 65,23 & 17,00 & 55,90 & 2,44 & 0,56 \\
\hline $\mathrm{CV}(\%)$ & 21,07 & 55,04 & 22,57 & 17,72 & 21,10 \\
\hline
\end{tabular}

*Valores seguidos de letra diferente diferem-se pelo teste de Tukey a 5\% de probabilidade de erro

Aos 60 dias de cultivo, houve interação significativa entre os clones e as épocas do ano (p $<0,05)$ para as variáveis porcentagens de sobrevivência e enraizamento, número e comprimento das raízes (Tabela 3). As maiores porcentagens de sobrevivência foram verificadas nas épocas do outono e inverno para os clones 06SM17 e 06SM15, e no inverno para as miniestacas dos clones 10SM07 e 06SM12. Este resultado provavelmente se deve ao fato destas épocas do ano apresentarem menores temperaturas e menores valores de irradiância, e consequentemente baixas taxas de transpiração das plantas (MARENCO; GONÇALVES; VIEIRA, 2001; MARENCO; LOPES, 2005). Esta hipótese é confirmada pelas menores porcentagens de sobrevivência das miniestacas dos quatro clones avaliados serem observadas no verão (Tabela 3), possivelmente ocasionadas pela maior perda de água dos propágulos vegetativos para a atmosfera causada pelas maiores temperaturas e irradiância desta estação. 
Tabela 3 - Porcentagens de sobrevivência e enraizamento, número e comprimento das raízes e porcentagem de calogênese em miniestacas coletadas de clones de erva-mate (Ilex paraguariensis A. St. -Hil.) em diferentes épocas do ano, independentemente do tratamento com AIB, aos 60 dias de cultivo.

Table 3 - Percentages of survival and rooting, number and length of roots and percentage of calogenesis in mini-cuttings collected from clones of erva mate (Ilex paraguariensis A. St. -Hil.) at different times of the year, regardless of IBA treatment, at 60 days of cultivation.

\begin{tabular}{|c|c|c|c|c|}
\hline \multirow{2}{*}{ Clones } & \multicolumn{4}{|c|}{ Épocas do ano } \\
\hline & Outono & Inverno & Primavera & Verão \\
\hline & \multicolumn{4}{|c|}{ Sobrevivência (\%) } \\
\hline 10SM07 & $71,78 \mathrm{Bb}^{*}$ & 88,26 Aa & $66,65 \mathrm{Bab}$ & $42,12 \mathrm{Ca}$ \\
\hline 06SM17 & $79,19 \mathrm{Aab}$ & $71,03 \mathrm{Ab}$ & $55,68 \mathrm{Bb}$ & $39,62 \mathrm{Ca}$ \\
\hline 06SM15 & $86,40 \mathrm{Aa}$ & $80,08 \mathrm{Aab}$ & $53,75 \mathrm{Bb}$ & $40,12 \mathrm{Ba}$ \\
\hline 06SM12 & 79,71 Aab & $84,08 \mathrm{Aa}$ & $71,68 \mathrm{Aa}$ & $33,62 \mathrm{Ba}$ \\
\hline Média & 79,27 & 80,86 & 61,94 & 38,87 \\
\hline \multirow[t]{2}{*}{ CV (\%) } & \multicolumn{4}{|c|}{21,07} \\
\hline & \multicolumn{4}{|c|}{ Enraizamento (\%) } \\
\hline 10SM07 & $12,54 \mathrm{Ac}$ & $8,05 \mathrm{Abb}$ & $2,49 \mathrm{Ba}$ & $3,00 \mathrm{Bc}$ \\
\hline 06SM17 & $26,00 \mathrm{Ab}$ & $13,23 \mathrm{Bb}$ & $4,23 \mathrm{Ca}$ & $11,94 \mathrm{BCb}$ \\
\hline 06SM15 & $58,07 \mathrm{Aa}$ & $63,39 \mathrm{Aa}$ & $9,75 \mathrm{Ca}$ & $24,13 \mathrm{Ba}$ \\
\hline 06SM12 & $11,94 \mathrm{Ac}$ & $10,40 \mathrm{Ab}$ & 6,19 Aa & $6,65 \mathrm{Abc}$ \\
\hline Média & 27,14 & 23,77 & 5,67 & 11,43 \\
\hline \multirow[t]{2}{*}{ CV (\%) } & \multicolumn{4}{|c|}{55,04} \\
\hline & \multicolumn{4}{|c|}{ Número de raízes } \\
\hline 10SM07 & 2,44 Aab & $1,40 \mathrm{Bc}$ & $1,40 \mathrm{Bc}$ & $1,53 \mathrm{Bb}$ \\
\hline 06SM17 & $2,37 \mathrm{Aab}$ & $2,22 \mathrm{Abc}$ & $2,62 \mathrm{Ab}$ & $2,19 \mathrm{Ab}$ \\
\hline 06SM15 & $3,26 \mathrm{Ba}$ & 3,84 Aba & 3,78 Aba & 4,87 Aa \\
\hline 06SM12 & $1,68 \mathrm{ABb}$ & $2,47 \mathrm{Ab}$ & $1,54 \mathrm{Bc}$ & $1,54 \mathrm{Bb}$ \\
\hline Média & 2,44 & 2,48 & 2,33 & 2,53 \\
\hline \multirow[t]{2}{*}{ CV (\%) } & \multicolumn{4}{|c|}{17,72} \\
\hline & \multicolumn{4}{|c|}{ Comprimento de raízes $(\mathrm{cm})$} \\
\hline 10SM07 & $0,43 \mathrm{Ac}$ & $0,44 \mathrm{Ac}$ & $0,40 \mathrm{Ba}$ & $0,24 \mathrm{Bb}$ \\
\hline 06SM17 & $0,69 \mathrm{Aab}$ & $0,72 \mathrm{Ab}$ & $0,45 \mathrm{Ba}$ & $0,44 \mathrm{Bb}$ \\
\hline 06SM15 & $0,93 \mathrm{Aa}$ & $0,98 \mathrm{Aa}$ & $0,55 \mathrm{Ba}$ & $0,94 \mathrm{Aa}$ \\
\hline 06SM12 & $0,62 \mathrm{Abc}$ & $0,47 \mathrm{Ac}$ & $0,41 \mathrm{Ba}$ & $0,36 \mathrm{Bb}$ \\
\hline Média & 0,67 & 0,65 & 0,45 & 0,49 \\
\hline \multirow[t]{2}{*}{ CV $(\%)$} & \multicolumn{4}{|c|}{21,10} \\
\hline & \multicolumn{4}{|c|}{ Calogênese (\%) } \\
\hline 10SM07 & $59,19 \mathrm{Bb}$ & $83,91 \mathrm{Aa}$ & $62,75 \mathrm{Ba}$ & $32,00 \mathrm{Ca}$ \\
\hline 06SM17 & $60,10 \mathrm{Ab}$ & $65,32 \mathrm{Ab}$ & 50,65 Aab & $28,62 \mathrm{Ba}$ \\
\hline 06SM15 & $72,92 \mathrm{Aa}$ & 74,74 Aab & $43,20 \mathrm{Bb}$ & $32,88 \mathrm{Ba}$ \\
\hline 06SM12 & $58,95 \mathrm{Bb}$ & 81,11 Aa & $64,48 \mathrm{Ba}$ & 23,56 Ca \\
\hline Média & 62,79 & 76,27 & 55,27 & 29,27 \\
\hline CV (\%) & \multicolumn{4}{|c|}{22,57} \\
\hline
\end{tabular}

*Valores seguidos de letra diferente, maiúscula na horizontal e minúscula na vertical, diferem-se pelo teste de Tukey a $5 \%$ de probabilidade de erro.

Quanto ao enraizamento adventício, as melhores respostas foram observadas em miniestacas do clone 06SM15, diferindo estatisticamente do clone 10SM07 quando coletadas nos meses do outono, inverno e verão (Tabela 3). Além de alta porcentagem de enraizamento, este clone também apresentou o maior comprimento das raízes aos 60 dias de avaliação (Tabela 3), o que provavelmente está relacionado à juvenilidade deste material genético.

Para os clones 10SM07 e 06SM17, as maiores porcentagens de enraizamento também foram observadas no outono e inverno. Esta resposta pode ter ocorrido pelo fato das plantas 
apresentarem altos teores de açúcares solúveis durante o outono e o inverno, devido às condições ambientais destas estações aumentarem a atividade das amilases e fosforilases, as quais promovem a hidrólise do amido para a formação de açúcares solúveis (OLIVEIRA et al., 2012a). Entretanto, como nesse estudo as miniestacas foram mantidas em casa de vegetação climatizada, a qual restringe as oscilações de temperatura, não houve a necessidade dos propágulos vegetativos manterem os altos níveis de açúcares para suportar o período de frio. Assim, provavelmente, as plantas reconstituíram os açúcares solúveis em grânulos de amido (SCHRADER; SAUTER, 2002). O amido constitui complexos blocos de macromoléculas, elementos estruturais e recursos energéticos, favorecendo o enraizamento adventício (HARTMANN et al., 2011). Em estudos de enraizamento de estacas de mirtileiro (Vaccinium ashei Reade) também foi verificado maior teor de amido nos ramos durante o inverno, o qual foi associado à maior taxa de enraizamento das estacas (OLIVEIRA et al., 2012a).

Independentemente do clone estudado, a menor porcentagem de enraizamento das miniestacas de erva-mate foi observada nas coletas realizadas na primavera e no verão, aos 60 dias de cultivo (Tabela 3), o que pode ser explicado devido a estas estações apresentarem temperaturas mais elevadas, possibilitando intenso crescimento vegetativo das plantas e alto nível de ácido giberélico. O ácido giberélico bloqueia a atividade auxínica no desenvolvimento do primórdio radicial, inibindo a formação de raízes nos propágulos vegetativos de determinadas espécies e genótipos (HAISSIG, 1972; ONO et al., 1994).

Quanto à porcentagem de calogênese, houve interação significativa entre os clones e as épocas do ano $(\mathrm{p}<0,05)$ em que foram realizadas as coletas das miniestacas (Tabela 3). A maior formação de calo foi verificada nas miniestacas dos quatro clones de erva-mate coletadas no inverno, sem diferir do outono e da primavera para o clone 06SM17, e do outono para o clone 06SM15, aos 60 dias de cultivo. Resultados similares foram verificados em estacas de caquizeiro (Diospyros kaki L.), nos quais a sazonalidade influenciou na capacidade calogênica dos propágulos vegetativos (SILVA; FAQUIM; CARVALHO, 2006). A formação de calo nos propágulos vegetativos pode ser um indicativo de enraizamento futuro das miniestacas de erva-mate coletadas nessas épocas do ano. Esta relação é evidenciada devido ao clone 06SM15 ter apresentado maior porcentagem de calogênese e de enraizamento das miniestacas. Segundo Oliveira et al. (2012b), as células desse tecido indiferenciado, denominado de calo, podem vir a se diferenciar e formar primórdios radiciais, caso sejam mantidos em condições de enraizamento por período adequado. Assim, trabalhos futuros avaliando o tempo ótimo de permanência das miniestacas de erva-mate em câmara úmida, bem como estudos anatômicos avaliando a possível relação entre a calogênese e o enraizamento adventício é de extrema necessidade, evitando que ocorra a retirada das miniestacas da câmara úmida antes do término do processo rizogênico.

Para o número de miniestacas enraizadas por minicepa de erva-mate, não houve interação significativa entre os clones e as épocas de coleta das brotações ( $p>0,05)$, aos 60 dias de cultivo (Figura 2). Os maiores números de miniestacas enraizadas por minicepa foram verificados com o clone 06SM15, sem diferir significativamente dos clones 06SM17 e 06SM12, independentemente da época do ano (Figura 2A). Cabe ressaltar que o clone 06SM15 além de apresentar o maior número de miniestacas enraizadas por minicepa $(15,50)$ também obteve a maior porcentagem de miniestacas enraizadas nas quatro épocas do ano, como observado na Tabela 3, o que sugere que este clone apresenta potencial para a produção massal de mudas de erva-mate.

O clone 10SM07 apresentou o menor número de miniestacas enraizadas por minicepa $(5,50)$, independentemente da época do ano, aos 60 dias de cultivo (Figura 2A). Este resultado, provavelmente, ocorreu devido às miniestacas do clone 10SM07 terem sido obtidas de minicepas produzidas pela estaquia convencional, ou seja, utilizando material vegetal coletado de árvores adultas. Dessa forma, os propágulos vegetativos deste clone apresentam maior grau de maturação se comparados as miniestacas coletadas de minicepas produzidas pela cultura de embriões zigóticos. Em plantas lenhosas, um dos principais efeitos da maturação é a redução na capacidade de enraizamento dos propágulos vegetativos (WENDLING; TRUEMAN; XAVIER, 2014). Esse efeito também foi observado na estaquia de erva-mate, sendo verificada a redução da porcentagem de enraizamento de $91,7 \%$ para $6,8 \%$ utilizando propágulos juvenis e maduros, respectivamente (SAND, 1989). 


\section{Figura 2 - Número de miniestacas enraizadas por minicepa de diferentes clones de erva- mate (Ilex paraguariensis A. St. -Hil.) (A) e em função das épocas do ano em que foram realizadas as coletas das miniestacas $(B)$, independentemente do tratamento com AIB. *Valores seguidos de letra diferente diferem-se pelo teste de Tukey a $5 \%$ de probabilidade de erro.}

Figure 2 - Number of mini-cuttings rooted by mini-stumps of different clones of erva mate (Ilex paraguariensis A. St. -Hil.) (A) and according to the seasons of the year that the mini-cuttings were collected (B), regardless of the IBA treatment. * Values followed by different letters differ by the Tukey test at $5 \%$ of error probability.

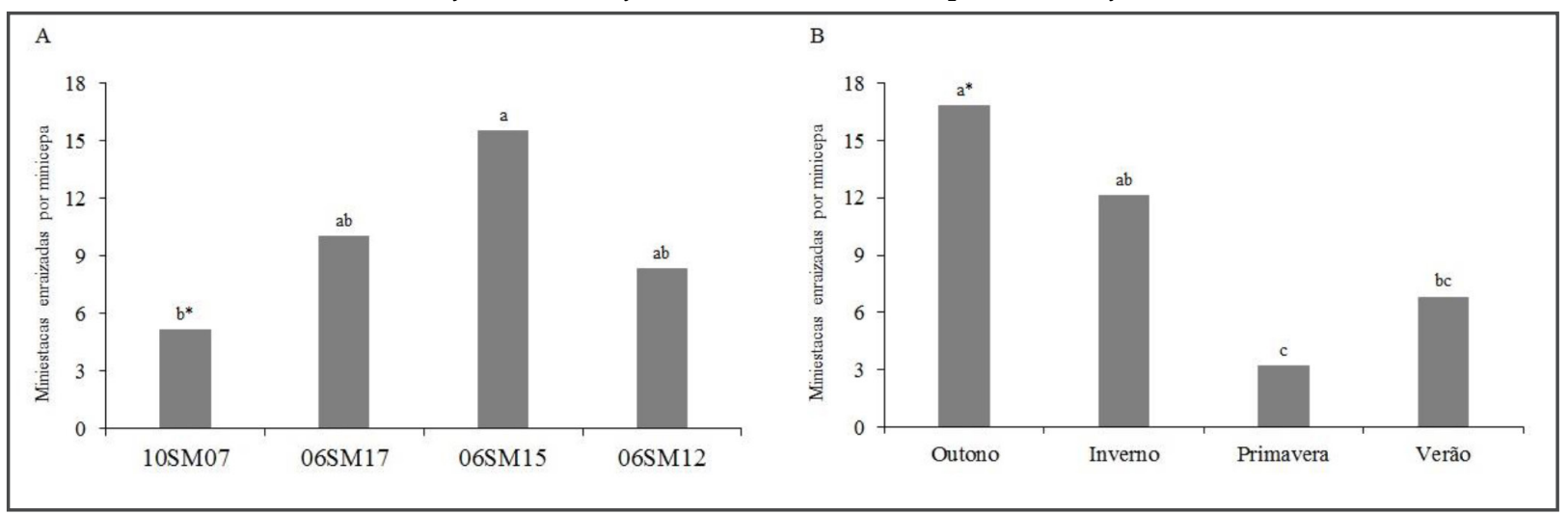

Fonte: Autores (2019)

Source: Authors (2019)

Quanto à época do ano em que foi realizada a coleta das brotações, os maiores números de miniestacas enraizadas por minicepa foram observadas no outono $(16,80)$ sem diferir do inverno $(12,10)$, independentemente do clone, aos 60 dias de cultivo (Figura 2B). Já o menor número de miniestacas enraizadas por minicepa de erva-mate foi verificado na primavera $(3,20)$, sem diferir estatisticamente do verão $(6,80)$. Deve ser salientado que o número de miniestacas enraizadas por minicepa consiste em uma variável que combina a produtividade de miniestacas por minicepas e o enraizamento adventício, permitindo determinar a quantidade de mudas que serão produzidas por minicepa de erva-mate, facilitando o dimensionamento do minijardim clonal conforme o número de mudas que o viveirista deseja produzir. A sazonalidade, apesar de ter influenciado na produtividade de miniestacas apenas do clone 10SM07 (Tabela 1), influenciou na porcentagem de enraizamento dos propágulos vegetativos (Tabela 3) e também no número de miniestacas enraizadas por minicepa (Figura 2B), sendo que as épocas do outono e inverno possibilitaram maior produção de mudas de erva-mate.

De maneira geral, os resultados deste estudo mostraram que as minicepas dos quatro clones de erva-mate apresentaram alta sobrevivência (100\%) em sistema de minijardim clonal, bem como produção constante de miniestacas dos clones 06SM17, 06SM15 e 06SM12 durante as quatro épocas do ano. O enraizamento de miniestacas de erva-mate não foi influenciado pelo uso de AIB, porém teve influência tanto da sazonalidade quanto de clones. Quanto à sazonalidade, o outono e/ou inverno possibilitaram as maiores porcentagens de enraizamento e comprimento das raízes formadas nas miniestacas dos quatro genótipos de erva-mate. As miniestacas do clone 06SM15 apresentaram as melhores porcentagens de enraizamento e o maior número de miniestacas enraizadas por minicepa nas quatro épocas do ano, o que permite concluir que este é um clone que possibilita a produção massal de mudas de erva-mate por miniestaquia.

\section{Conclusões}

A produtividade das minicepas de erva-mate foi constante nas quatro épocas do ano para três dos quatro clones avaliados. 
O enraizamento das miniestacas foi influenciado tanto pelo genótipo quanto pela sazonalidade, sendo que os propágulos vegetativos coletados no outono e no inverno possibilitaram as maiores respostas de enraizamento das miniestacas de erva-mate.

A produção de mudas de erva-mate por miniestaquia pode ser realizada sem o tratamento com AIB.

\section{Referências}

ALFENAS, A. C. et al. Clonagem e doenças do eucalipto. Viçosa, MG: Editora UFV, 2009. 500 p.

BANDINELLI, M. G. et al. Concentração dos sais e da sacarose do meio MS na multiplicação in vitro e na aclimatização de batata. Horticultura Brasileira, Brasilia, v. 31, n. 2, p. 242-247, 2013.

BITENCOURT, J. et al. Enraizamento de estacas de erva-mate (Ilex paraguariensis A. St.-Hill.) provenientes de brotações rejuvenescidas. Revista Brasileira de Plantas Medicinais, Botucatu, v. 11, n. 3, p. 277-281, 2009.

BORGES, S. R. et al. Enraizamento de miniestacas de clones híbridos de Eucalyptus globulus. Revista Árvore, Viçosa, MG, v. 35, n. 3, p. 425-434, 2011.

BRONDANI, G. E. et al. Ácido indolbutírico em gel para o enraizamento de miniestacas de Eucalyptus benthamii Maiden \& Cambage x Eucalyptus dunnii Maiden. Scientia Agraria, Curitiba, v. 9, n. 2, p. 153-158, 2008a.

BRONDANI, G. E. etal. Enraizamento de miniestacas de erva-mate sob diferentes ambientes. Pesquisa Florestal Brasileira, Colombo, n. 57, p. 29-38, 2008b.

BRONDANI, G. E. et al. Dynamics of adventitious rooting in mini-cuttings of Eucalyptus benthamii x Eucalyptus dunnii. Acta Scientiarum Agronomy, Maringá, v. 34, n. 2, p. 169-178, 2012.

CARDOZO JUNIOR, E. L.; MORAND, C. Interest of mate (Ilex paraguariensis A. St.- Hil.) as a new natural functional food to preserve human cardiovascular health - a review. Journal of Functional Foods, Canadá, v. 21, p. 440-454, 2016.

CUNHA, A. C. M. C. M. et al. Relação do estado nutricional de minicepas com o enraizamento de miniestacas de eucalipto. Revista Brasileira de Ciência do Solo, Viçosa, MG, v. 33, p. 591-599, 2009.

FERRIANI, A. P.; ZUFFELLATO-RIBAS, K. C.; WENDLING, I. Miniestaquia aplicada a espécies florestais. Revista Agro@mbiente On-line, Boa Vista, v. 4, n. 2, p. 102-109, 2010.

FOWLER, J. A. P.; STURION, J. A. Aspectos da formação do fruto e da semente na germinação da erva-mate. Colombo: EMBRAPA Florestas, 2000.5p.

GREENWOOD, M. S.; DAY, M.; SCHATZ, J. Separating the effects of tree size and meristem maturation on shoot development of grafted scions of red spruce (Picea rubens Sarg.). Tree Physiology, Canadá, v. 30, p. 459-468, 2010.

HAISSIG, B. E. Meristematic activity during adventitious root primordium development influences of endogenous auxin and applied gibberellic acid. Plant Physiology, Rockville, v. 49, p. 886-892, 1972.

HARTMANN, H. T. et al. Plant propagacion: principles and practices. New Jersey: Prentice Hall, 2011. 915 p.

HORBACH, M. A. et al. Micropropagação de plântulas de erva-mate obtidas de embriões zigóticos. Revista Ciência Rural, Santa Maria, v. 41, n. 1, p. 113-119, 2011.

KRATZ, D. et al. Produção de mudas de erva-mate por miniestaquia em substratos renováveis. Revista Floresta, Curitiba, v. 45, n. 3, p. 609-616, 2015.

MARENCO, R. A.; GONÇALVES, J. F. C.; VIEIRA, G. Leaf gas exchange and carbohydrates in tropical trees differing in successional status in two light environments in central Amazonia. Tree Physiology, Canadá, v. 21, p. 1311-1318, 2001.

MARENCO, R. A.; LOPES, N. F. Fisiologiavegetal: fotossíntese, respiração, relações hídricas e nutrição mineral. 
Viçosa, MG: Editora UFV, 2005.451 p.

MARQUES, T. C. L. L. S. M. et al. Crescimento inicial do Paricá (Schizolobium amazonicum) sob omissão de nutrientes e de sódio em solução nutritiva. Cerne, Lavras, v. 10, n. 2, p. 184-195, 2004.

NAGAOKA, R. E. et al. Efeito do AIB no desenvolvimento de mudas clonais em genótipos de erva-mate. Enciclopédia Biosfera, Goiânia, v. 9, n. 17, p. 1182-1191, 2013.

OLIVEIRA, R. J. P. et al. Teores de carboidratos em estacas lenhosas de mirtileiro. Revista Brasileira de Fruticultura, Jaboticabal, v. 34, n. 4, p. 1199-1207, 2012a.

OLIVEIRA, Y. et al. Substratos, concentrações de ácido indolbutírico e tipos de miniestacas no enraizamento de melaleuca (Melaleuca alternifolia Cheel). Revista Brasileira de Plantas Medicinais, Botucatu, v. 14, n. 4, p. 611$616,2012 b$.

ONO, E. O.et al. Enraizamento de estacas de Platanus acerifolia, tratadas com auxinas. Pesquisa Agropecuária Brasileira, Brasilia, v. 29, n. 9, p. 1373-1380, 1994.

REZENDE, R. K. S. et al. Características morfológicas e produtividade do crambe em função da adubação nitrogenada. Revista Agraria, Dourados, v. 8, n. 29, p. 279-286, 2015.

ROSA, L. S.et al. Efeito da dose de nitrogênio e de formulações de substratos na miniestaquia de Eucalyptus dunnii Maiden. Revista Árvore, Viçosa, v. 33, n. 6, p. 1025-1035, 2009.

SAMBIASSI, C.; ESCALADA, A. M.; SCHMALKO, M. E. Extration optimization of soluble compounds of yerba maté. Brazilian Archives of Biology and Technology, Curitiba, v. 45, n. 2, p. 189-193, 2002.

SAND, H. A. Propagación agamica de la yerba mate (Ilex paraguariensis S. Hil.). Cerro Azul: INTA Estación Experimental Agropecuaria Misiones, 1989.11 p.

SANSBERRO, P. et al. Plant regeneration of Ilex paraguariensis (Aquifoliaceae) by in vitro culture of nodal segments. Biocell, Mendoza, v. 24, n. 1, p. 53-63, 2000.

SANTIN, D. et al. Crescimento de mudas de erva-mate fertilizadas com N, P e K. Scientia Agraria, Curitiba, v. 9, n. 1, p. 59-66, 2008.

SCHRADER, S.;SAUTER,J.J. Seasonal changes of sucrose-phosphate synthase and sucrose synthase activities in poplarwood (Populusx Canadensis Moench "robusta") and their possible role in carbohydrate metabolism. Journal of Plant Physiology, Stuttgart, v. 159, p. 833-843, 2002.

SILVA, E. T.; BICCA NETO, H.; FOLTRAN, B. N. Materiais de cobertura na produção de mudas de erva-mate (Ilex paraguariensis St. Hill). Scientia Agraria, Curitiba, v. 8, n. 1, p. 103-109, 2007.

SILVA, I. D.; FAQUIM, R.; CARVALHO, R. I. N. de. Calogênese em diferentes estacas de caquizeiro tratadas com frio e ácido indolbutírico. Scientia Agraria, Curitiba, v. 7, n. 1-2, p. 113-118, 2006.

TITON, M. et al. Eficiência das minicepas e microcepas na produção de propágulos de clones de Eucalyptus grandis. Revista Árvore, Viçosa, v. 27, n. 5, p. 619-625, 2003.

WENDLING, I.; DUTRA, L. F. Solução nutritiva para conduçãode minicepas de erva-mate (Ilex paraguariensis St. Hil.) em sistema semi-hidropônico. Colombo: EMBRAPA Florestas, 2008. 4 p.

WENDLING, I.; DUTRA, L. F.; GROSSI, F. Produção e sobrevivência de miniestacas e minicepas de erva-mate cultivadas em sistema semi-hidropônico. Pesquisa Agropecuária Brasileira, Brasília, v. 42, n. 2, p. 289-292, 2007.

WENDLING, I.; SANTIN, D. Propagação e nutrição de erva-mate. Brasilia: EMBRAPA, 2015. 195 p.

WENDLING, I.; TRUEMAN, S. J.; XAVIER, A. Maturation and related aspects in clonal forestry-part II: reinvigoration, rejuvenation and juvenility maintenance. New Forests, [s. l.], v. 45, p. 473-486, 2014.

WENDLING, I.; XAVIER, A. Gradiente de maturação e rejuvenescimento aplicado em espécies florestais. Revista Floresta e Ambiente, Seropédica, v. 8, n. 1, p. 187-194, 2001. 